\title{
A Global Overview of Monitoring and Evaluation (M\&E) and its Meaning in the Local Government Context of South Africa
}

MASUKU, Ngengelezi W.K. | IJEOMA, EOC

\section{Abstract}

$T^{2}$

he article explores the global overview

of $M \& E$ from the ancient governance perspective that has been ignored by the modern government in the African contest. African M\&E approach is required in the local rural municipalities due to its complex and diverse set of problems. These problems are as a result of leadership dichotomy which is witnessed between Amakhosi and municipal authorities. Amakhosi have a role to hold municipal authorities accountable from a Citizen-Based Approach.

The underlying philosophy of the article is not about the discourse of the modernists and traditionalists around the evolution of $M \& E$, but is how and in what ways M\&E should be designed and planned for the implementation of a successful relevant M\&E approach for local rural municipalities. The article made use of secondary data, gathered from various sources. Case studies of the international countries were also sourced through desktop to ascertain their best practice on M\&E. The article concludes that the lack of $M \& E$ approach for the local government in the rural municipalities requires the Participatory Monitoring and Evaluation (PM\&E) approach to allow stakeholders, including Amakhosi to assess the performance of the rural municipalities. The study is significant to the local and internal public scholarship of public administration since it bring approaches in M\&E policy in the field of public administration. For example, indigenous African knowledge is critical in knowledge management.

Keywords: Planning, Monitoring and Evaluation, Accountability, Traditional Leaders, Governance 


\section{Introduction}

The advent of globalisation has produced growing pressures on governments and organisations around the world to be more responsive to the demands of the stakeholders, which include government departments, parliaments, citizens, Amakhosi (traditional leaders), the private sector, Non-Governmental Organisations (NGOs), civil society, international organisations, and donors. They are demanding good governance, accountability and transparency, greater development, effectiveness, and delivery of tangible results (Kusek and Rist 2004: 1). In light of the above, the local government has a huge responsibility to fulfil this responsibility since it is the coal-face of service delivery. This requires a relevant $M \& E$ approach for local government to foster accountability.

The purpose of this article is to review and reflect on where the world once was, against where it is now, and where it is heading in terms of M\&E. This particularly relates to traditional governance from Stone Age information perspective which seems to be forgotten by the modern government. For example, the uThungulu District Municipality (UDM) Auditor General Report (2011) indicated that the municipality did not involve Amakhosi in the Integrated Development Plan, and M\&E in the rural municipalities.

From a traditionalist point of view, literature has been very scarce in the evolution of global M\&E in the traditional governance approach. This has led to the ignorance of the traditional governance and their ancient intellectual property, which is key in the modern local governance, particularly in the rural municipalities. From a modernist perspective, the meaning of the $M \& E$ in the global context has not only been critical for both national and provincial government in SA, but it cuts across all the spheres of government, including the local government. In this regard, it was not only significant for urban local government, but is also critical for the rural local government. The next paragraph will be examining the conceptualisation of $M \& E$ to clarify the difference between monitoring and evaluation.

\section{Definition of M\&E}

M\&E are two distinct elements, but they complement each other. M\&E should be understood as a managing tool that provides clarity to all stakeholders as to why certain activities are undertaken. Monitoring is a continuous function that uses systematic collection of data on specified indicators to provide management and the main stakeholders of an on-going development intervention. This is defined with indications of 
the extent of progress and achievement of objectives and progress in the use of allocated funds. Evaluation is the systematic and objective assessment of an on-going or completed project, programme or policy, in relation to its design, implementation and results. The aim is to determine the relevance and fulfilment of objectives, development efficiency, effectiveness, impact and sustainability (Public Service Commission 2008).

\section{Research questions}

- What is a global overview of M\&E in relation to its meaning in South Africa local government?

- What is the view of the traditionalists and modernists on matters of governance and its M\&E application approaches?

- What should be a suitable M\&E alternative of the modern local governance in the rural municipalities?

\section{Research objectives}

- To assess a global overview of M\&E in relation to its meaning in South Africa, particularly the local government.

- To ascertain the scholarly debates from the traditionalists and modernists on matters of governance and its M\&E application approaches.

- To recommend PM\&E as future approach of the modern local governance in the rural municipalities.

\section{Methodology}

A qualitative descriptive and exploratory study approach was used in this journal article as a way of drawing secondary sources. According to Mouton 2001:79, exploratory research is based on the research subject that has not been defined. From a descriptive research perspective, the researcher has been in the UDM long enough to observe the silent problem regarding the participation of Amakhosi in the modern governance through Monitory and Evaluation (M\&E) in UDM, which has not been explored. It is in this context that the researcher is exploring the possibilities of their involvement in modern government. Exploratory research helps to determine whether to proceed with a research idea and how to approach it. 
Case studies in public administration prepare future administrators for challenges, particularly those left by apartheid legacies. In addition, they will be able to know how to restructure their departments; draw up policy proposals, etc. International experiences must be introduced to challenge the local experiences that they are faced with for broader understanding of various issues and problems solving (Schutte, Schwella and Fitzgerald, 1995: 4). Given this background, the three selected comparative case studies, included the Swaziland, Botswana, and Saudi Arabia Interestingly enough, the importance of these countries shows that traditional governance is being integrated into modern governance, particularly in planning and M\&E. Lessons born out of experiences will be drawn within the context of South Africa for the success of the study within uThungulu District Municipality, which main case study in this article.

The researcher also consulted different sources to ensure quality of the article. Subsequently, relevant sources of this research were fairly and professionally scrutinised, understood and tested with the available literature for the purpose of the research. Interalia, it included scan-reading, comprehensive and critical reading, and writing down ideas. Subsequently, the article reviewed a large number of publications in a limited period of time. The purpose was to identify the relevant publications and apply them in the research (Brynard and Hanekom, 1997:12-14).

\section{Limitation of the study}

The study did not focus on the technical expert of M\&E in relation to Amakhosi. This is because Amakhosi do not have the capacity on how to develop M\&E in the modern context.

\section{M\&E in the traditional government from the ancient context}

The modernist argued that the evolution M\&E started in the western countries. However, traditionalists argued that $M \& E$ is not a new concept in Africa, but it has existed in the form of traditional governance during the Stone Age. It is so unfortunate that literature in the global overview of M\&E overlooked the evolution from the Stone Age context as discussed in this section (Rugege 1998).

Rugege 1998 claimed that traditional governance has been the basis of local government. In this regard, community participation in decision-making and reporting 
was based on the agreed plans through traditional gathering (imbizo). Izinduna ${ }^{1}$ (head chiefs) from different places were reporting on their different places based on progress, and interventions thereof. The issue of accountability was highly emphasised based on the responsibilities that were delegated by Inkosi to Izinduna. The essence of the traditional governance was that the community was represented through Izinduna in decision-making. The community was updated with respect to the plans as well as progress being made in their areas.

\section{Reporting and Citizen based evaluation of traditional leaders}

Pre-colonial traditional leaders were answerable to their communities and its structures. Instruments of state policy charged with carrying out instructions from the state. The ancient approach reveals that decisions that affected the traditional community were usually made by the traditional leader who consulted with councillors representing the interests of the community. It should however, be noted that not all traditional leaders were 'angels' or benevolent, generous, and carrying towards their constituencies. By virtue of nature, some of them were tyrannical and oppressive, and this was not the interest of their people. As a result, people showed their disapproval of unpopular Amakhosi by moving to the areas of the more popular leaders. In other regions, unpopular Amakhosi were deposed or killed (Zungu, 1999-2001).The researcher is of the view that this approach is required in the modern local government. In this regard, poor performing and arrogant local municipal authorities should be removed.

The principle of the traditional leadership has been defined by the historians and anthropologist as they attest that traditional leaders ruled largely with the consent of their people. From the performance management perspective, those Izinduna that were not performing were removed at any time if their performance was unsatisfactory. The Induna's function was to represent his ward at the tribal council, to allocate land to new residents (who had been approved by the chief-in-council and accepted by the existing community members), to collect taxes, maintain law and order as well as the resolving of minor cases that, if unsettled, would be referred to the chief. However, before a leader was removed, there were serious measures that were being looked at in terms of capacity building, coaching, and other assistance (Zungu, 1999-2001).

\footnotetext{
1 Izinduna refers to the headman or traditional councillor for a village or a ward in the traditional authority."
} 


\section{Training and development}

The ward council, which is similar to the chief-in-council, would assist the Induna in performing community services. Each ward also has several functionaries that perform tasks on behalf of the inkosi. There was Induna yezinsizwa ${ }^{2}$ who would be responsible for training and exercising young warriors. He would be answerable the chief and from time to time would be called on to present his men to the chief. This authority system continues down to the unit of the nuclear family, which consists of a "head", who has final authority. It is argued that tasks were or are handed out according to the age, capability and accepted practices within the particular traditional authority. After the sons married they would not leave their father's house, but would become part of the homestead or $u m u z i^{3}$. As an imizi grew with time, it would develop into a settlement where clusters of the clan would be found (Zungu, 1999-2001).

\section{Global M\&E trends from a modern context}

In the context of Africa, literature review reveals that Egypt is a father and founder of M\&E in the world. The ancient Egyptians regularly monitored their country's outputs in grain and livestock production more than 5,000 years ago. This shows that M\&E is certainly not a new phenomenon in Africa. Developed countries followed suit in the modern M\&E, particularly those of the Organisations for Co-Operation and Development (OECD), have had as many as 20 years or more years of experience in M\&E. Both OECD and developed countries have created evaluation cultures and $M \& E$ systems in response to varying degrees in response to internal and external pressures. Developed countries have further chosen a variety of starting points for implementing results-based $M \& E$ systems. This is including whole-of-government, enclave, and mixed approaches (Kusek and Rist, 2004: 2).

The researcher argues that the evolution of $M \& E$ has introduced various approaches like Result Based Monitoring and Evaluation (RBM\&E). It is essentially a special public management tool that governments can use to measure and evaluate outcomes, and then feed this information back into the on-going processes of governance and decision-making The researcher is of the view that it is so unfortunate that other approaches like PM\&E has not been given attention which is also necessary to

\footnotetext{
${ }^{2}$ Induna yezinsiwa refers to the leader of a team of the traditional young man

${ }^{3}$ Umuzi refers to a homestead. In a plural form is imizi (homesteads).
} 
complement the RBM\&E. PM\&E is a process through which stakeholders at various levels engage in monitoring or evaluating a particular project, program or policy; share control over the content, the process and the results of the M\&E activity and engage in taking or identifying corrective actions.

\section{Evolution of the participatory M\&E in the global context}

The beauty of this approach is that it departs with a participatory approach. It also inculcates the principle of involvement and empowerment, and citizen based approach (Kusek and Rist 2004:23). It is regrettable that not all countries have applied this approach in the M\&E context, including SA, argues the researcher.

\section{Table 1: Evolution of M\&E in South Africa}

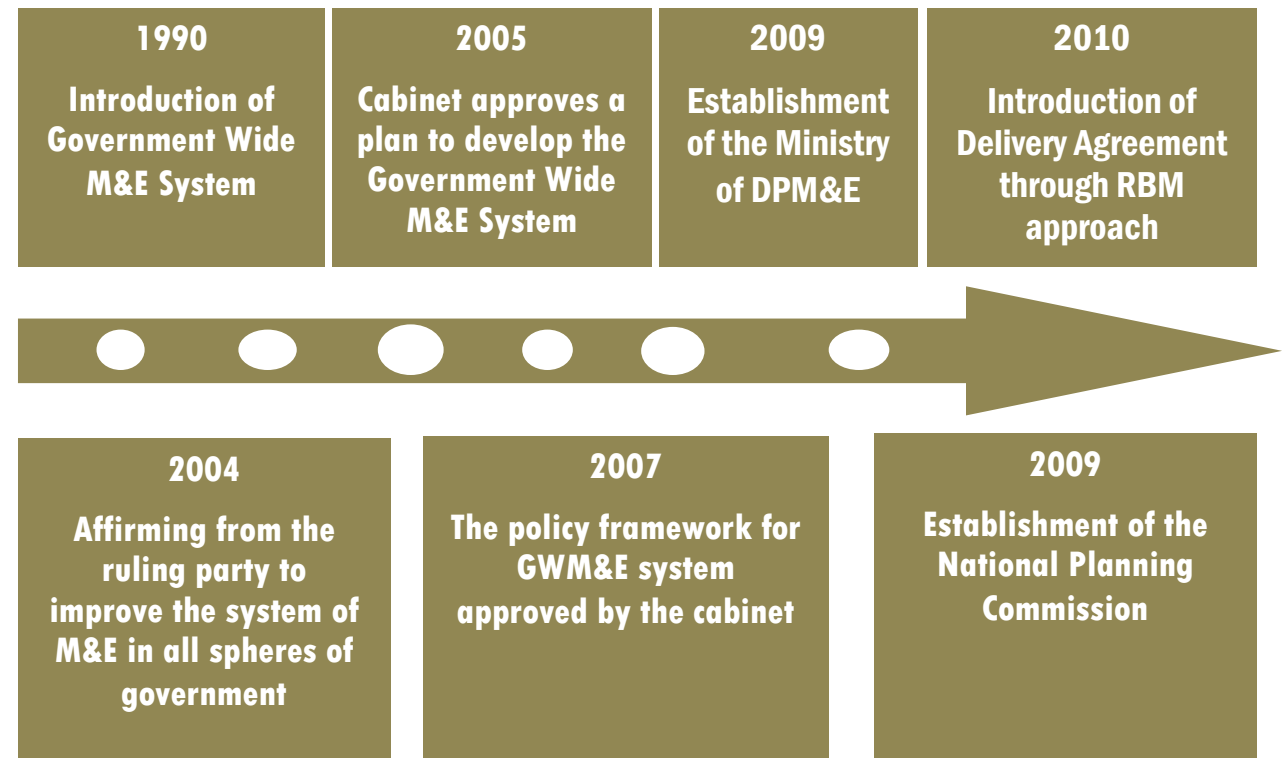

Source: Bosch 2012. Evolution of M\&E in SA

Poor programme performance of the government attracted the attention of the African National Congress (ANC) government to monitor and evaluate the programme performance. Subsequently, $M \& E$ found a space in the lens of the government. Bester 2009 argued that M\&E practice in the South African government is at an interesting 
point in its evolution. Previously M\&E was a term known only to a handful of government officials who had been exposed to the practice through donor agencies and through exposure to $M \& E$ in other countries. The above table traces the humble genesis of $M \& E$ in the South African public sector. In the first 5 years of the post-apartheid government, it is argued that very few departments engaged in any systematic M\&E of their policies and programmes. The early attempts by government to introduce Government-Wide M\&E (GWM\&E) have its inceptions at the late 1990s. Unsuccessful cases of these attempts have led to the renewal effort at GWM\&E in 2004. The 2004 Election Manifesto of the Ruling Party gave birth to the identification priority of M\&E (Bester 2004).

The intention was to improve the implementation of all these programmes, through stronger M\&E units at national, provincial and local level. This heralded the approval of a plan geared to develop the GWM\&E in 2005 across government. The Presidency was given the task of leading the effort, with other key role players, namely, the National Treasury, the Department of Public Service and Administration, the Department of Provincial and Local Government, the South African Management Development Institute, the Public Service Commission and Statistics South Africa (Bester 2009). The policy framework for the GWM\&E system was approved in 2007. However, it is noted that the introduction of GWM\&E System came with challenges. These challenges emanated from the original confusion reigned when it was thought to be an information technology system (BesteR 2004).

Since its inception, the GWM\&E System has spearheaded the National Development Indicators project. The government has released an annual publication on 76 development indicators linked to the development priorities of government and in some instances to the Millennium Development Goals. The Programme Performance Information Framework is in use by government departments, though the extent of usage is variable (Bester 2004).

The 2009 elections heralded the new administration under the stewardship of President Zuma. A question at heart of $M \& E$ has been around its strategic location in the institution/organisation. Hitherto, M\&E experts or practitioners, policy analysts, and policy makers are in the same vein that its strategic location must be within the head of the institutions. President Zuma demonstrated his resolve to improve public sector performance and service delivery. In this regard, he established the Ministry of the 
Department of Performance Monitoring and Evaluation (DPM\&E) and National Planning Commission (NPC) in 20009. This has catapulted M\&E to greater prominence. Bosch (2011) argued that the establishment of NPC was based on the premise that, to get results depend son much more than good financial management. Government agreed that for any organisation, public or private, delivery depends on the quality not only of the financial side of its balance sheet, but also of its real side - the quality of its people, and how effectively they are deployed and led (Bester 2004).

Indeed, this establishment has generated a great deal of interest in the evaluation of communities around the world. In September 2009, the Ministry issued a Green Paper: Improving Government Performance: Our Approach. Through this approach, a set of 12 Outcomes in 2010 were approved. This set the strategic agenda for government. This was followed by the introduction of the National Evaluation Framework in 2011. It is the last of the three policy elements introduced in the Policy Framework for the GWM\&E system as approved by Cabinet in 2005. The other two elements are programme performance information and quality of statistical data. Its main purpose is to promote quality evaluations which can be used for learning to improve the effectiveness and impact of government. Subsequently, it should reflect on what is working and what is not working and revising interventions accordingly (Bester, 2004).The researcher proposes the focus should be on Citizen-Based M\&E which should be informed by $P M \& E$ in rural areas.

\section{Aims of the GWM\&E}

According to Bester (2004), the aims of GWM\&E are as follows:

- To serve as an integrated and encompassing framework of M\&E principles, practices and standards for use in all spheres of Government and

- $\quad$ To serve as an apex-level information system that draws on component systems.

\section{Result Based M\&E}

This is a powerful public management tool introduced by the World Bank. It can be used to help policy-makers and decision makers to track progress and demonstrate the impact of a given project, program, or policy. It differs from traditional implementationfocused M\&E defined by compliance. In this regard, it moves beyond an emphasis on inputs and outputs to a greater focus on outcomes and impact (Kusek and Rist 2004:1). 
The researcher is of the view that RBM\&E is operating at the strategic level, which creates difficulties for the local citizens to be in touch with the provincial and national government. It is in this context that PM\&E approach should be applied in local government in order to complement the RBM\&E based on the fact that PM\&E operate at the local level.

\section{Challenges facing developing countries in M\&E}

According to the proceedings of the SAMEA 2013, some of the problems discussed below are applicable to the developed countries. However, most of these challenges are found mostly in the developing countries including SA.

\section{Designing M\&E}

Designing M\&E in a developing country is difficult and should not to be underestimated. This process cannot happen overnight. Despite The fact that many of the developing countries are considering a serious construction of M\&E system, it should not be dismissed that many of them found it too complicated, too demanding, or too sophisticated for a developing country to undertake. Finding good information on how to develop M\&E system is a remedy for them (Kusek and Rist 2004: 32-34). In light of the above, the researcher argues that $M \& E$ approach for local government, particularly in the rural municipalities is also a challenge. As a result, rural municipal authorities are not held accountable.

\section{Context challenges}

The major concern is that the current M\&E is a western approach, and it cannot address all African problems, particularly in the rural areas. Africa as a developing country is a unique continent based on its cultural dynamics, history, politics, knowledge systems, and languages. $M \& E$ is still a challenge in Africa based on the fact that the current $M \& E$ approaches are borrowed from the international countries that are outside the scope of the African context. M\&E practitioners always focus on indicators instead of context. As a result, the continent is missing a lot of context in the program design (SAMEA 2013). 


\section{Cooperation and coordination}

Many public institutions are still facing coordinating challenges. There is a culture of working in silos versus uniformity in the government departments. Institutions of higher learning are always left behind; instead of funding them to run the M\&E academic courses (SAMEA 2013). In light of the above, the researcher argues that government is not consulting Amakhosi, which is the important layer of government in the rural municipalities.

\section{Institutional challenges}

Many developing countries are still struggling to put together strong and effective institutions. Some may require transformation in their public service guided by well transformed legal and regulatory frameworks (SAMEA 2013). The researcher is of the view that proper transformation of local government, particularly in the rural municipalities will be deemed acceptable once the layer of traditional governance is recognised in the municipal processes, particularly in planning, and M\&E.

\section{Lack of stakeholder involvement}

The main challenge is that many developing countries have missed the importance of stakeholder participation in planning and M\&E (SAMEA 2013). This has deprived the opportunity for local citizens to make inputs in decision-making, particularly in M\&E. As a result, the existing $M \& E$ approach which is sometimes assumed as being elite-driven, has not benefited the communities especially in rural municipalities, argues the researcher.

\section{Compliance M\&E}

Compliance M\&E, instead of RBM\&E approach has been a culture in the public sector. This has not showcased the real results on the ground. The focus on outputs than outcomes and impact is still a challenge. A question at heart from the performance management perspective has been that "so what if outputs are achieved, but not results" (Kusek and Rist 2004: 32-34). 


\section{linking planning, budget, priorities, and M\&E}

The current challenge in many countries is the budget constraints towards developing and institutionalising their M\&E system. Linking budget, planning, and priorities, and $M \& E$ is a challenge that is also experienced by developed counties (Kusek and Rist 2004: 32-34).

\section{Lack of integration with other strategic approaches}

The problem with $M \& E$ is that it is not integrated with the strategic plans of the organisation. This is conceptually and contextually incorrect because there is no way that strategic planning, and M\&E can work in silos. Both strategic planning and M\&E should find each other. Immediately a strategic plan is developed, these strategic plans should be monitored and evaluated (SAMEA 2013).

\section{M\&E challenges in South Africa:}

\section{Lack of evidence and truth}

Sometimes government officials forget that $M \& E$ is about to be human in term of telling the truth to the citizens. This has been witnessed by incorrect reports. For example, President Zuma indicated that he has been misled by the officials. There is a culture of isolating the principle of fairness in terms of involving the community as the rightful stakeholders. For example, traditional leaders are always excluded in planning, and M\&E (Sithole and Mbhele, 2008; SAMEA 2013).

\section{Elite capture versus stakeholder involvement}

Elite capture is a problem in Africa. Most of the problems that have been identified are vague. Lack of citizen's participation as the beneficiary has been missing. Most of the problems have been identified, and captured by the elites at the expense of the citizens (SAMEA 2013).

\section{Lack of coordination}

M\&E is a strategic management function because it works with other plans. This requires working in collaboration with other people. The big challenge is that there are many solutions, and the government is expected to run them. Assumption made here is that 
this is not working because there is no one size fit all. Instead, it is a matter of adaptation, and customize in the government environment. Many government departments are still working in silos instead of sharing knowledge (SAMEA 2013).

\section{Implementation of priorities and their impact}

The South African public sector is still focusing on outputs than on outcomes as supposed to be the key focus of the RBM\&E. Finding ways of assessing the impact of their policies and programs is still a challenge. This is particularly true especially on how South Africa assesses its progress in achieving the Millennium Development Goals (SAMEA 2013).

\section{Absence of the M\&E legislation}

The government's Green Paper states that it may consider introducing legislation on M\&E. It is not clear what the aim of such legislation would be as there are already Acts, regulations and policies that require government departments to account for their use of resources and for their performance. Specific legislation to enforce M\&E practices will not necessarily improve M\&E. Legislation could have the unintended consequence of getting people to focus on minimal compliance (Bosch 2011).

\section{Capacity constraints}

The continuous challenge faced by the government departments is that their personnel are not capacitated on M\&E, particularly On Evaluation. There is too much dependency on consultants (SAMEA 2013).

\section{Absence of theory of change}

Theory of change applies to every project. It starts with the problem identification, and end with the solution. Minister of DPME, Chabane asserted that it is however noticeable that most of the government programs are solution-driven without problem identification from a situational, and feasibility perspective. The government's inability to respond to the citizens' needs is based on common sense without understanding the causes of the problems. There is a culture of providing drugs instead of providing them clean water (SAMEA 2013). 


\section{Failure to recognise mistakes}

This is a challenge that is also facing developed countries. Many government institutions are rushing for good results irrespective of mistakes. A need to recognise failure and plan for them is a challenge in the public sector (SAMEA 2013).

Information and Communication Technology (ICT) and donors versus M\&E methods

The government is facing a serious challenge of convincing donors to accept $M \& E$ methods other than ICT as a means of evaluating the results. Donors are manipulating the government because they control the purse strings. Changing the dominating ICT community in evaluation is a daunting challenge facing the government. These ICT tools are not contributing on the needs of the local citizens (SAMEA 2013).

\section{Evolution of M\&E in the local government context}

The advent of $M \& E$ in South Africa did not attract the attention of both provincial and national government. But the poor performance of the municipalities calls for the application of M\&E in local government. The environment in which local government has to operate is fragile due to its complex challenges that are faced with. The advent of democracy has awakened the people about their rights, and also their involvement in decision-making. However, the researcher argues that strategic planning for PM\&E has never been implemented for both traditional leadership and modern local government. The reality is that municipalities in South Africa are currently undergoing transformation. This requires flexibility and strategic planning with emphasis on $P M \& E$ where the municipal authorities signed performance agreements with traditional leaders from a citizen based M\&E to enforce accountability (Waldt et al. 2007).

\section{Challenges of local government:}

\section{Elite capture versus stakeholder involvement}

The above challenges also affect local government in SA. Lack of citizen's participation through Amakhosi as the beneficiary has been missing in the rural municipalities, argues the researcher. 


\section{The concerns of Auditor-General, and the performance of municipalities}

Rural development is a buzz word in the government priorities to deal with socioeconomic issues towards meeting the requirements of a developmental state. The AG raised concern on the performance of municipalities, and rural municipalities are a big concern. Among other issues of poor performance in rural municipalities, are leadership and planning. Leadership contestation between the government and Amakhosi takes its toll at the expense of the citizens. Sometimes these contestations give a space for the rural municipal authorities to do things without being held accountable (Stone 2013)

Wimble 2007 argued that Amakhosi should be encouraged to monitor and evaluate performance in the rural municipalities. In the same vein, Sithole2008 stated that Amakhosi have a role in leading, advising, participating, monitoring and evaluating the successes of any project or program that is aimed at developing rural people. It is in this context that the article suggests $P M \& E$ as a relevant approach for $M \& E$ in rural municipalities, born out of the global M\&E evolution (Sithole 2005).

\section{Qualitative descriptive and exploratory study findings of PM\&E Planning improvement}

Lessons learned in Swaziland are that PM\&E is inculcating the principles of participatory planning from the early phases of the projects, implementation, and M\&E. The government of Botswana has expressed its commitment to bottom-up planning and has developed decentralized planning machinery at the district level. The purpose of this is to realise the significance of people's participation in development planning. The traditional leaders and structures (Kgotla) are closely involved in formulation, implementation and monitoring of district plans processes. Traditional leaders have a role in coordinating the district plans and monitor their implementation. Kgotla serves as a forum for consultation with people and their participation at different stages of formulation and implementation of development plans. This traditional forum serves as a channel of two-way communication between the government and the people in the process of bottom-up planning (Sharma 2010).

The Ministry of Tinkhundla Administration and Development has a mandate to facilitate the management of region development and to facilitate the promotion of 
service delivery at Tinkhundla and Chiefdoms levels. Tinkhundla is the foundation for the bottom-up development planning process and the delivery of local services in partnership with central government. The decision-making process of Swaziland centres around the community needs. For example, Parliament can recommend for the change of a village into a town or any project. However, the King cannot agree with the new initiative without the will of His subjects. In actual fact, programmes or project planning starts with communities. Any service delivery needs start with them regarding their inputs. Municipal authorities cannot come or initiate service delivery needs of the community e.g. water, whereas the community's first choice was electricity. However, most of the modern countries are seldom open to community consultation (Mkhonta 2007).

\section{Participation improvement}

The interesting case article of Swaziland is that there is no project that is passed by the Prime Minister without the involvement of Amakhosi. Although the king is the head of the state, he ensures that the Prime Minister considers the views of traditional leaders. Lessons learned in Swaziland are that it is inculcating the principles of participatory planning from the early phases of the projects, implementation, and monitoring and evaluation. Interestingly enough, the king has a bigger voice to ensure that the Prime Minister accounts to him in terms of the views of Amakhosi in relation to the community projects that are initiated by the government. This is a realistic democracy in terms of community voices unlike in the South African context where e-tolling system was approved irrespective of the lament of the Gauteng communities. This shows the weakness of the modern governance in terms of planning principles from a participatory perspective (Mkhonta 2007).

\section{Listening improvement}

Listening rather than educe is a major principle of the Saudi monarchy. This is done through informal face-to-face meetings which fall under the umbrella of participation. These meetings addressed the needs of the community from a planning phase to a decision-making phase (Al-Saadon, 2012). 


\section{Prioritisation of issues (negotiation) from international lessons}

The principle of negotiation is very important for developing common objectives. This is called win-win situation to avoid conflicts. There is no way that district authorities can pass decisions without getting the voice of the communities through their tribal leaders. The major concern is to reach harmony in the decision-making process. This is important for ensuring a stable government against conflict (AI-Saadon 2012).

There is no decision-making without negotiating with the chiefdoms as representatives of the community. All service delivery needs are negotiated with the communities through their chiefdoms. The importance of negotiation is to consider the views of traditional leaders in terms of priorities in relation to the development of their areas (Mkhonta 2007).This means that all stakeholders need to reach a consensus about what to do with the evaluation of findings, how to solve problems and how to improve the program's effectiveness (Anatole 2005).

\section{Reporting improvement}

With this, Amakhosi will be updated with the development in their areas. They will feel important because they also own government processes. From the Swaziland lessons of experience, it is learnt that Inkundla has a development committee ('ubuchopho') elected from the various constituency chiefdoms in its area for a five-year term. Buchopho brings to the inkundla all matters of interest and concern to their various chiefdoms. It then takes back to the chiefdoms the decisions of inkundla. The chairman of ubuchopho is elected at the inkundla and is called indvuna. Planning and participation are the principles at the heart of Swaziland from the traditional governance perspective in rural areas (Mkhonta 2007). In terms of accountability, the Prime Minister accounts to the King or Parliament. More importantly, he also has to give feedback based on what was agreed upon with the chiefdom (Al-Saadon 2012).

\section{Initiation of Citizen Based M\&E (accountability to the community)}

As alluded to above, the provincial government oversees the local offices of the central government and municipal officials. In some of the provinces, the governors that are appointed by the King that have chosen to hold a public meeting. This allows the people through their tribal leaders to voice their grievances in government programmes and projects for the service delivery improvement. This means that tribal leaders have a role 
to oversee the local government performance. The bottom line is that the governors are compelled to report or account to the king based on service delivery issues at community level (Al-Saadon 2012).

\section{Contribution to the general results of the RBM\&E}

From onset, the article has been arguing that it is not its intention to critique the existing RBM\&E system or Outcome Based Monitoring and Evaluation. However, PM\&E will complement the RBM\&E. In this regard, the PM\&E from a bottom-up approach will allow the community through Amakhosi to raise their issues on municipal performance. In a way, they will become reliable sources on information.

The community through traditional governance will assess the performance of the municipality based on what was agreed upon in terms of plans or priorities. Consequently, this will lead to the achievement of the long term results of the government from the Result-Based M\&E. The PM\&E approach will talk to great areas of needs of the community through Amakhosi. From the power of measuring results if you can demonstrate results, you can win the public support (Kusek and Rist 2004:11).

\section{CONCIUSION}

The article argued that global overview of M\&E in SA did not give a meaning for only national and provincial government, but it has also implications for the local government, particularly in the rural municipalities. This has awakened the stakeholders to put pressures on government to demand accountability, and service delivery excellence. According to the article, indications are that there is the absence of $M \& E$ approach for local government. In addition, the context challenges (culture, languages, and indigenous stakeholders like Amakhosi in the rural municipalities) have been overlooked by the elite approaches. It was learnt from the international experience that PM\&E approach is relevant for the rural municipalities.

\section{RECOMENDATIONS}

In light of the above, it is recommended that PM\&E approach should be used a relevant approach for the rural municipalities In this regard, Amakhosi have a role to play to foster accountability to the rural municipal authorities. This approach allows the citizens to participate in planning, and also to assess the performance of the municipalities. In 
addition, it might complement the Result-Based M\&E which is still operating at the strategic level. The successful implementation of this approach will depend on the integration of Amakhosi into modern local government. They should also be supported with necessary resources in order to perform their duties.

\section{List of References}

- Anatole, S. 2005. Public Involvement through PM\&E. Available http://cura.unbc.ca/cm/PM\&Epaper.pdf. [Accessed 2012-05-07]

- Bester, A. 2009. Evaluation of public policies in South Africa: Governance, Independence and Credibility. Available http://web.undp.org/evaluation/workshop/nec/2009/documents/papers/AngelaBester.pdf. [Accessed 2012-08-23].

- Bosch, L. 2011. The Evolution of M\&E in South Africa. Available http://copmfdrafrica.ning.com/profiles/blogs/the-evolution-of-monitoring-amp-evaluationin-south-africa. [Accessed 2012-10-11].

- Bynard, P A and Hanekom, S X 1997. Introduction to research in Public Administration. Pretoria. JL van Schaik Publishers.

- Keulder, C.1998. Traditional leaders and Local Government in Africa. Lessons for South Africa. Pretoria. HSRC.

- Kusek, J Z and Rist, R C. 2004. A handbook for Development Practitioners. Ten Steps to a Result-Based Monitoring and Evaluation System. Washington D C. The World Bank.

- Mkhonta, P B.2007 Local government in Swaziland. Requirements for competent administration in urban areas. Available http://upetd.up.ac.za/thesis/available/etd11152007 162851/unrestricted/00front.pdf [Accessed 2013-05-08].

- Mouton, E B J. 2001. The practice of social research. Cape Town AB Press.

- Naidoo, K and Simmonds, S. (2007). Paper for Public Service Commission Internal Human Resource Conference: Some reflections on public sector performance. Available http://www.google.co.za/\#site =\&source =hp\&q=some + reflections + in + public + sector + perfo 
rmance\%2C+Naidoo\&oq=some+reflections +in+public +sector+performance $\% 2 \mathrm{C}+$ Naidoo \&gs_l=hp.3...38841.68965.0.69465.57.34.1.6.6.1.624.3760.2-

2j1j4j2.9.0...0.0...1c.1.9.hp.0rjl8e8aV0M\&bav=on.2,or.\&bvm=bv.45373924,d.d2k\&fp=7e844e2 $1 c f 03 e 5 e 1 \& b i w=1093 \& b i h=422 .$. [Accessed 2013-06-02.

- Public Service Commission. 2008. Basic Concepts in M\&E. Available at http://www.psc.gov.za/documents/docs/guidelines/PSC\%206\%20in\%20one.pdf [Accessed 2013-08-03].

- Rugege, S. 1998 Traditional leadership and its future role in governance. Available http://www.ldd.org.za/images/stories/Ready_for_publication/V72_Traditional_leadership.pdf. [Accessed 2013-01-16].

- $\quad$ SAMEA. 2013. 4th Biennal SAMEA Conference: September Conference Materials. Available http://www.samea.org.za/index.php? module= pagesetter\&type=user\&func=viewpub\&tid $=4$ \&pid=59. [Accessed 2014-02-18].

- Sharma, K C. 2010. The role of traditional structures in local governance for local development the case of Botswana. Available http://info.worldbank.org/etools/docs/library/153055/BOTSWANA.pdf. [Accessed 2013-0319].

- Shutte, L.B, Schwella, E \& Fitzgerald, P. (1995). Changing Public and Development Management: South African Cases.

- Sithole, P and Mbhele, T. 2008. Fifteen Year Review on Traditional Leadership. Research Paper.

Available http://www.google.co.za/url?url=http://www.dta.gov.za/index.php/publications/documents/ doc_download/2-fifteen-year-review-on-traditional-

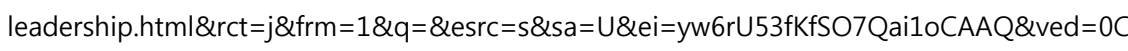
BMQFjAA\&sig2=Cb4q2AqZ4novDBauA9NH0g\&usg=AFQjCNEpIX2eMG7RLd-

PZc0PTX5WoIDDLQ. [Accessed 2013-01-02].

- Waldt, G, Venter, A, WAlt, C, Phutigae, K, Khalo,T, Niekerk,D, Nealer, E 2007. Municipal Management. Serving the people. Cape Town. Juta.

- Stone, S. 2013. National Auditor-general warns that state of municipal finances is worsening. Available http://www.bdlive.co.za/national/2013/08/14/auditor-general-warnsthat-state-of-municipal-finances-is-worsening.[Accessed 2013-02-16]

- (Uthungulu Annual Report 2012/13). Serious about Service Delivery. Available http://mfma.treasury.gov.za/Documents/06.\%20Annual\%20Reports/2012- 
A Global Overview of Monitoring and Evaluation \& its Meaning in the Local Govt Context of SA 25

13/03.\%20District\%20municipalities/DC28\%20uThungulu/DC28\%20Uthungulu\%20Annual\% 20Report\%202012-13.pdf. [Accessed 2013-03/20].

- Wimble, K. 2006. Leadership - A Critical Need in Rural South Africa. Available http://www.thevalleytrust.org.za/?page=news\&news=detail\&id=27. [Accessed 2013-02-07].

- Zungu, S. 2001. Independent Project Trust. Traditional Leaders. A KwaZulu Natal Study. Available http://www.ipt.co.za/tradleadbook.htm. [Accessed 2013-02-24].

\section{AUTHORS' CONTACT:}

\section{MASUKU, Ngengelezi W.K. $\mid$ IJEOMA, EOC}

Eastern Cape Legislature Chair \& Head

Bisho Dept of Public Administration

Email: wmasuku@ecleg.gov.za University of Fort Hare

Email: eijeoma@ufh.ac.za 